\title{
ADP and platelets: the end of the beginning
}

\section{Donna Woulfe, Jing Yang, and Lawrence Brass}

Departments of Medicine and Pharmacology and the Center for Experimental Therapeutics, University of Pennsylvania, Philadelphia, Pennsylvania, USA

Address correspondence to: Lawrence Brass, University of Pennsylvania, Room 913 BRB-II, 421 Curie Boulevard,

Philadelphia, Pennsylvania 19104, USA. Phone: (215) 573-3540; Fax: (215) 573-2189; E-mail: Brass@mail.med.upenn.edu.

Along with thrombin and collagen, ADP has long been recognized for its contribution to the propagation of platelet activation at sites of vascular injury. However, recent studies have brought a new appreciation of the extent of that contribution and identified the two G protein-coupled receptors that appear to be largely responsible for platelet responses to ADP: P2Y1, which activates phospholipase C (1), and P2Y12, which suppresses cAMP formation so that activation can occur (Figure 1) $(2,3)$. P2Y12 (also known as P2T, P2Yac, and SP1999) was identified last year by two teams of investigators using distinctly different strategies (2, $3)$. Now, in this issue of the JCI, Carolyn Foster and her colleagues at Schering-Plough Research Institute describe the consequences of deleting the gene encoding P2Y12 in mice (4). Their results help to validate parts of the current model for platelet activation by ADP. They also bring to a conclusion a phase of research in which platelet responses to ADP were initially characterized, the contribution of heterotrimeric $G$ proteins was recognized, and the existence of more than one class of ADP receptor was established. Given the growing use of

\section{Figure 1}

ADP and platelet activation. Platelet activation by potent agonists such as thrombin or collagen causes the release of secondary agonists such as thromboxane $A_{2}\left(\mathrm{TxA}_{2}\right)$ and the secretion of ADP from platelet dense granules. Platelet responses to $A D P$ require the coordinate activation of two $G$ protein-coupled receptors, P2Y1 and $\mathrm{P} 2 \mathrm{Y} 12$, whose actions are described in the text. Drugs such as Ticlopidine and Clopidogrel block activation of P2Y12. Mechanisms that place a limit on unwarranted platelet activation include CD39 on the surface of endothelial cells, which hydrolyzes ADP to AMP, and $\mathrm{PGI}_{2}$ and $\mathrm{NO}$, which increase the concentration of CAMP and CGMP within platelets. antiplatelet agents that target P2Y12 in patients with cardiovascular disease, this is a good opportunity to review the role of ADP in platelet activation and consider some of the questions that have yet to be answered.

\section{The end of the beginning}

The formation of a stable platelet plug at sites of injury requires both the initiation and the propagation of platelet activation. Initiation is typically provided by exposed collagen and vWF in the vessel wall and by the local generation of thrombin once tissue factor/VIIa complexes have formed. Propagation occurs when additional platelets are recruited into a growing hemostatic plug by released or secreted secondary agonists such as thromboxane $\mathrm{A}_{2}\left(\mathrm{TxA}_{2}\right), \mathrm{ADP}$, and the $\alpha$-granule product, Gas6 (5). ADP is actively secreted from platelet dense granules but is also passively released from damaged erythrocytes and endothelial cells. Most platelet agonists, including ADP,

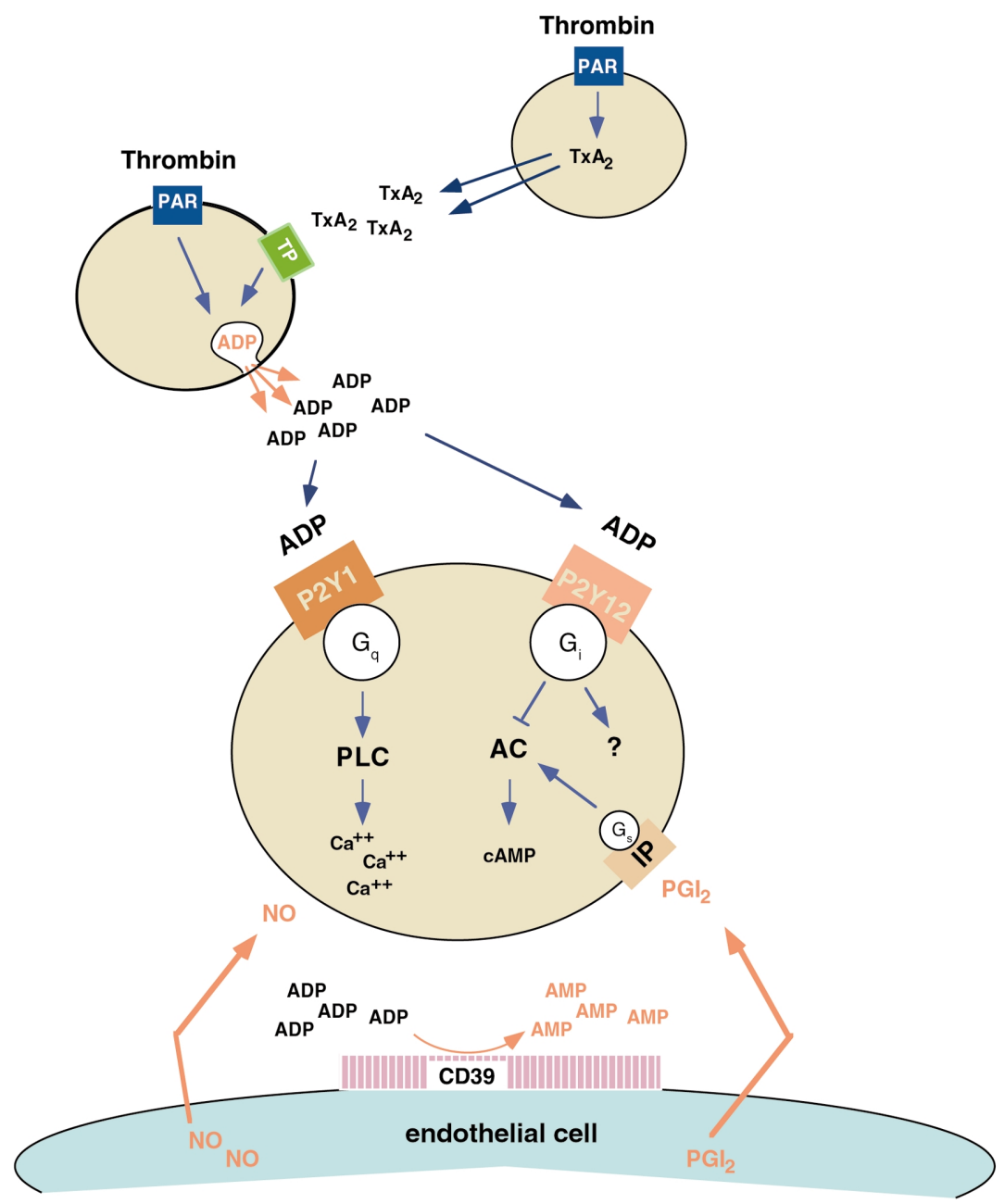


activate platelets via cell surface receptors coupled to heterotrimeric GTPbinding proteins or $G$ proteins. Platelets contain representatives of all four of the known families of $G$ proteins: $G_{q}, G_{i}, G_{12}$, and $G_{s}$. The first three of these have been shown to mediate the effects of agonists that activate platelets; agonist receptors may couple to one, two, or all three. A variety of processes prevent inappropriate platelet activation or place limits on the extent of platelet activation, including endothelium-derived $\mathrm{PGI}_{2}$ and $\mathrm{NO}$, which raise platelet cAMP and cGMP levels, and CD39, which hydrolyzes ADP to inactive AMP. $\mathrm{PGI}_{2}$ stimulates cAMP formation by activating adenylyl cyclase via receptors on the platelet surface that are coupled to $\mathrm{G}_{\mathrm{s}}$ (Figure 1).

Shortly after stimulation with ADP, platelets undergo a shape change (6), a rise in phospholipase $\mathrm{C}$ activity, and an increase in cytosolic $\mathrm{Ca}^{2+}(7)$. ADP also suppresses cAMP formation, an effect that is critical for platelet activation to occur. Work with purinederived agonists and antagonists of platelet function helped to define the existence of multiple receptors for ADP that work coordinately to produce platelet responses to ADP. One of these is a ligand-gated ion channel, $\mathrm{P} 2 \mathrm{X} 1$, which is activated by the ATP analog $\alpha, \beta$-MeATP, allowing an influx of extracellular $\mathrm{Ca}^{2+}(7,8)$. Conversely, another ATP analog, ARL-66096 (now shown to be a P2Y12 antagonist), blocks both ADP-stimulated aggregation and the inhibition of adenylyl cyclase but fails to inhibit phospholipase $\mathrm{C}$ activation or shape change at the same concentrations (7). Thus, even before the receptors were identified, these and many other observations supported the existence of two $G$ protein-coupled receptors for ADP on platelets: one that inhibits cAMP synthesis (presumably via a $\mathrm{G}_{\mathrm{i}}$ family member) and one that activates phospholipase $\mathrm{C}$ and causes shape change (presumably via a $\mathrm{G}_{\mathrm{q}}$ and possibly a $\mathrm{G}_{12}$ family member). Since antagonists at either receptor inhibit platelet aggregation in response to ADP, activation of both receptors has been thought to be required for aggregation (9). This observation and others suggest that, in general, activation of both $\mathrm{G}_{\mathrm{i}^{-}}$and $\mathrm{G}_{\mathrm{q}}$-mediated pathways is required to cause platelet aggregation (10). Interestingly, ADP is the only platelet agonist known to split this task between two receptors, one coupled to $G_{q}$ but not $G_{i}$, and the other coupled to $\mathrm{G}_{\mathrm{i}}$ but not $\mathrm{G}_{\mathrm{q}}$.

The $\mathrm{G}_{\mathrm{q}}$-coupled ADP receptor, $\mathrm{P} 2 \mathrm{Y} 1$, was the first to be cloned and is responsible for platelet shape change and $\mathrm{Ca}^{2+}$ mobilization (1). Platelets from mice that lack the $\alpha$ subunit of $\mathrm{G}_{\mathrm{q}}$ display ADP-related platelet defects that are similar in nature to platelets from mice that lack P2Y1: they neither change shape nor aggregate (11-13). However, $\mathrm{G}_{\mathrm{q}}$-deficient platelets retain the ability to change shape in response to agonists other than ADP, indicating that $G_{q}$ mediates the ADP-dependent rearrangement of actin filaments that results in platelet shape change, but a member of another $G$ protein family (probably $\mathrm{G}_{12}$ ) mediates these cytoskeletal changes in response to other agonists $(6,11,14)$.

The $\mathrm{G}_{\mathrm{i}}$-coupled ADP receptor, $\mathrm{P} 2 \mathrm{Y} 12$, was recently identified by two different groups of investigators $(2,3)$. The studies reported in this issue by Foster et al. (4) describe the consequences of its inactivation. As was predicted from inhibitor studies and from the phenotype of a patient lacking functional P2Y12 (15), platelets from mice lacking P2Y12 do not aggregate normally in response to ADP. They retain the P2Y1-associated responses, including shape change and phospholipase $\mathrm{C}$ activation, but lack the ability to inhibit cAMP formation by adenylyl cyclase. The $\mathrm{G}_{\mathrm{i}}$ family member associated with $\mathrm{P} 2 \mathrm{Y} 12$ responses appears to be primarily $\mathrm{G}_{\mathrm{i} 2}$, since platelets from $\mathrm{G}_{\mathrm{i} 2 \alpha}$-deficient mice have an impaired response to ADP (our unpublished observations; see also ref. 16), while those lacking the $\alpha$ subunits of the related $G_{i}$ family members, $G_{z}$ and $G_{i 3}$, respond normally (our unpublished observations; see also ref. 17).

\section{Beyond the end of the beginning}

The identification of the receptors that mediate platelet responses to ADP, the development of antagonists that target each of the known receptors, and the successful knockouts of the genes encoding P2Y1, P2Y12, $\mathrm{G}_{\mathrm{q} \alpha}$, and $\mathrm{G}_{\mathrm{i} 2 \alpha}$ have brought an increased appreciation of the contribution of ADP to platelet plug formation in vivo. Absence of P2Y12 $(2,15,18)$ produces a hemorrhagic phenotype in humans, albeit a relatively mild one. Deletion of either $P 2 Y 1$ or $P 2 Y 12$ in mice prolongs the bleeding time and impairs platelet responses not only to ADP, but also to thrombin and $\mathrm{TxA}_{2}$, particularly at low concentrations $(4,12,13)$. Since platelet $\mathrm{TxA}_{2}$ receptors do not couple directly to $\mathrm{G}_{\mathrm{i}}$ family members, platelet aggregation induced by $\mathrm{TxA}_{2}$ requires the secretion of ADP to inhibit adenylyl cyclase (19). The availability of mice deficient in either P2Y1 or P2Y12 makes it possible to assess the relative contributions of each receptor to platelet activation in vivo. It also provides an opportunity to breed these defects onto a prothrombotic or proatherogenic genetic background, such as those of Factor V Leiden and apoE1-deficient mice, to determine how ADP signaling through these receptors contributes to plateletrelated pathology. Lack of P2Y1 has already been shown to improve survival in mouse models of thrombosis following the injection of platelet agonists (12) and tissue factor (20). Generalizing from such studies may be risky, however, both because of possible intrinsic differences between mice and people and because the complete loss of the receptor may not prove to be equivalent to administering a receptor antagonist. Lifelong loss of a gene encoding a signaling molecule may evoke compensatory changes that are not seen following acute treatment with antagonists.

One immediate benefit of the identification of P2Y1 and P2Y12 is the potential to use the isolated receptors for the screening and development of additional drugs to treat patients with cardiovascular and cerebrovascular disease. In fact, two existing thienopyridine compounds, Ticlopidine and Clopidogrel, that target P2Y12 have been shown to have clinically useful antiplatelet activity (21). Newer ones are being developed (22). Many of these drugs target P2Y12 by an irreversible mechanism involving the generation of a reactive metabolite, which delays both the onset and resolution of their antiplatelet effects. Ticlopidine and Clopidogrel have been shown to cause the development in a subset of patients of a thrombotic thrombocytopenic purpura-like state characterized by a microangiopathic hemolytic anemia, intravascular platelet activation, and thrombocytopenia (23). Although the mechanisms underlying this event are not entirely clear, identification of P2Y12 offers hope that drugs can be developed that retain their potency as platelet activation inhibitors but lack this toxicity. 
The identification of P2Y1 and P2Y12 leaves open many questions about how agonists activate platelets. For example, the profound effects on platelet responses to agonists, seen in response to small changes in intracellular cAMP concentration, are not entirely understood (24). Multiple targets for cAMP-dependent protein kinases have been identified in platelets, but in most cases there is little information on how phosphorylation regulates function. In addition, although the suppression of CAMP synthesis is clearly one of the roles of ADP in platelets, P2Y12 and other receptors that are coupled to $G_{i}$ family members may do considerably more than that. Daniel et al. (25) have shown that membranepermeable inhibitors of adenylyl cyclase do not restore platelet responses to ADP when P2Y12 is blocked. Similarly, we have found that adenylyl cyclase inhibitors do not restore responses to epinephrine in platelets from mice that lack the $G_{i}$ family member $G_{z}$ (ref. 17 and our unpublished observations). In theory, activated $\mathrm{G}_{\mathrm{i}}$ family members in platelets can signal through both their GTP-bound $\alpha$ subunits $\left(G_{\alpha}\right)$ and $\beta \gamma$ heterodimers $\left(\mathrm{G}_{\beta \gamma}\right)$. So far most of the attention has been on inhibition of cAMP synthesis, but additional effectors for $\mathrm{G}_{\mathrm{i}^{-}}$ derived $G_{\alpha}$ include the Src family of tyrosine kinases, as well as a number of candidates that bind to the activated forms of $G_{i}$ and $G_{z}$ in yeast two-hybrid screens. Among these candidates are the GTPaseactivating proteins for the Ras family member Rap 1b; the transcription factor Eya2; and the $G_{\alpha}$-regulating protein, RGSZ. Known targets for $\mathrm{G}_{\beta \gamma}$ include phospholipase C $\beta$, PI 3-kinase- $\gamma, \mathrm{K}^{+}$ channels, and some members of the GRK family of receptor kinases.
It remains unclear which of these effectors are expressed in platelets and what roles they play in platelet responses to $\mathrm{G}_{\mathrm{i}}$-coupled agonists such as ADP. Most of the intracellular network of signaling mechanisms that link platelet ADP receptors with the exposure of platelet fibrinogen receptors an event that is required for platelet aggregation by all agonists - also remains to be defined.

1. Jin, J.G., Daniel, J.L., and Kunapuli, S.P. 1998. Molecular basis for ADP-induced platelet activation. II. The P2Y1 receptor mediates ADPinduced intracellular calcium mobilization and shape change in platelets. J. Biol. Chem. 273:2030-2034.

2. Hollopeter, G., et al. 2001. Identification of the platelet ADP receptor targeted by antithrombotic drugs. Nature. 409:202-207.

3. Zhang, F.L., et al. 2001. ADP is the cognate ligand for the orphan $G$ protein-coupled receptor SP1999. J. Biol. Chem. 276:8608-8615.

4. Foster, C.J., et al. 2001. Molecular identification and characterization of the platelet ADP receptor targeted by thienopyridine antithrombotic drugs. J. Clin. Invest. 107:1591-1598.

5. Angelillo-Scherrer, A., et al. 2001. Deficiency or inhibition of Gas 6 causes platelet dysfunction and protects mice against thrombosis. Nat. Med. 7:215-221.

6. Paul, B.Z.S., Daniel, J.L., and Kunapuli, S.P. 1999 Platelet shape change is mediated by both calcium-dependent and -independent signaling pathways: role of $\mathrm{p} 160$ Rho-associated coiled-coil-containing protein kinase in platelet shape change. $J$. Biol. Chem. 274:28293-28300.

7. Daniel, J.L., et al. 1998. Molecular basis for ADPinduced platelet activation. I. Evidence for three distinct ADP receptors on human platelets. J. Biol. Chem. 273:2024-2029.

8. MacKenzie, A.B., Mahaut-Smith, M.P., and Sage, S.O. 1996. Activation of receptor-operated cation channels via $\mathrm{P}_{2 \mathrm{X} 1}$ not $\mathrm{P}_{2 \mathrm{~T}}$ purinoceptors in human platelets. J. Biol. Chem. 271:2879-2881.

9. Jin, J.G., and Kunapuli, S.P. 1998. Coactivation of two different $G$ protein-coupled receptors is essential for ADP-induced platelet aggregation Proc. Natl. Acad. Sci. USA. 95:8070-8074.

10. Pulcinelli, F.M., et al. 1999. Concomitant activation of $G_{i}$ protein-coupled receptor and protein kinase $\mathrm{C}$ or phospholipase $\mathrm{C}$ is required for platelet aggregation. FEBS Lett. 460:37-40.

11. Offermanns, S., Toombs, C.F., Hu, Y.H., and
Simon, M.I. 1997. Defective platelet activation in $\mathrm{G} \alpha_{\mathrm{q}}$-deficient mice. Nature. 389:183-186.

12. Léon, C., et al. 1999. Defective platelet aggregation and increased resistance to thrombosis in purinergic $\mathrm{P}_{2} \mathrm{Y}_{1}$ receptor-null mice. J. Clin. Invest. 104:1731-1737.

13. Fabre, J.E., et al. 1999. Decreased platelet aggregation, increased bleeding time and resistance to thromboembolism in $\mathrm{P}_{2} \mathrm{Y}_{1}$-deficient mice. Nat. Med. 5:1199-1202.

14. Ohlmann, P., et al. 2000. ADP induces partial platelet aggregation without shape change and potentiates collagen-induced aggregation in the absence of G $\alpha$ q. Blood. 96:2134-2139.

15. Nurden, P.F., et al. 1995. An inherited bleeding disorder linked to a defective interaction between $\mathrm{ADP}$ and its receptor on platelets. Its influence on glycoprotein IIb-IIIa complex function. J. Clin. Invest. 95:1612-1622.

16. Yuan, Y.P., et al. 1999. The von Willebrand factorglycoprotein Ib/V/IX interaction induces actin polymerization and cytoskeletal reorganization in rolling platelets and glycoprotein Ib/V/IX transfected cells. J. Biol. Chem. 274:36241-36251.

17. Yang, J., et al. 2000. Loss of signaling through the $G$ protein, $G_{z}$, results in abnormal platelet activation and altered responses to psychoactive drugs. Proc. Natl. Acad. Sci. USA. 97:9984-9989.

18. Cattaneo, M., and Gachet, C. 1999. ADP receptors and clinical bleeding disorders. Arterioscler. Thromb. Vasc. Biol. 19:2281-2285.

19. Paul, B.Z.S., Jin, J.G., and Kunapuli, S.P. 1999. Molecular mechanism of thromboxane $\mathrm{A}_{2}$-induced platelet aggregation: essential role for $\mathrm{P}_{2} \mathrm{~T}_{A C}$ and $\alpha_{2 \mathrm{~A}}$ receptors. J. Biol. Chem. 274:29108-29114.

20. Léon, C., et al. 2001. Key role of the $\mathrm{P}_{2} \mathrm{Y}_{1}$ receptor in tissue factor-induced thrombin-dependent acute thromboembolism: studies in $\mathrm{P}_{2} \mathrm{Y}_{1}$-knockout mice and mice treated with a $\mathrm{P}_{2} \mathrm{Y}_{1}$ antagonist. Circulation. 103:718-723.

21. Bennett, J.S. 2001. Novel platelet inhibitors. Annu. Rev. Med. 52:161-184.

22. Sugidachi, A., et al. 2001. Antiplatelet action of R99224, an active metabolite of a novel thienopyridine-type $\mathrm{G}_{\mathrm{i}}$-linked $\mathrm{P} 2 \mathrm{~T}$ antagonist, CS-747. Br J. Pharmacol. 132:47-54.

23. Bennett, C.L., et al. 2000. Thrombotic thrombocytopenic purpura associated with clopidogrel. $N$ Engl. J. Med. 342:1773-1777.

24. Keularts, I.M.L.W., Van Gorp, R.M.A., Feijge, M.A.H., Vuist, W.M.J., and Heemskerk, J.W.M 2000. $\alpha_{2 \mathrm{~A}}$-adrenergic receptor stimulation potentiates calcium release in platelets by modulating cAMP levels. J. Biol. Chem. 275:1763-1772.

25. Daniel, J.L., Dangelmaier, C., Jin, J.G., Kim, Y.B., and Kunapuli, S.P. 1999. Role of intracellular signaling events in ADP-induced platelet aggregation. Thromb. Haemost. 82:1322-1326. 